Original article

\title{
Oral health care: The experience of Australian paediatricians
}

\author{
Archana Koirala ${ }^{\mathrm{a}, \mathrm{b}}$ \\ archana.koirala@heath.nsw.gov.au \\ Elodie O'Connor ${ }^{\mathrm{c}}$ \\ elodie.oconnor@mcri.edu.au \\ Richard Widmer $^{\mathrm{d}}$ \\ richard.widmer@health.nsw.gov.au
}

Nicky Kilpatrick ${ }^{\mathrm{e}, \mathrm{f}, \mathrm{g}}$

nicky@,bassdata.com.au

Sharon Goldfeld ${ }^{\mathrm{c}, \mathrm{f}}$

sharon.goldfeld@rch.org.au

\begin{abstract}
Affiliations: ${ }^{a}$ Centre of Infectious Diseases and Microbiology, Sydney, Australia. ${ }^{b}$ University

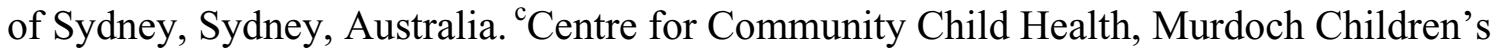
Research Institute, Royal Children's Hospital, Melbourne, Australia; ${ }^{\mathrm{d}}$ Department of Paediatric Dentistry, Children's Hospital at Westmead, Sydney, Australia; ${ }^{\mathrm{e} D e p a r t m e n t ~ o f ~}$ Plastic and Maxillofacial Surgery, Royal Children's Hospital, Melbourne, Australia; ${ }^{f}$ Department of Paediatrics, University of Melbourne, Melbourne, Australia; ${ }^{g}$ Plastic Surgery Research, Murdoch Children's Research Institute, Royal Children's Hospital, Melbourne, Australia.
\end{abstract}

Address correspondence to: Professor Sharon Goldfeld, Centre for Community Child Health, Royal Children's Hospital, 2 East Clinical Offices, 50 Flemington Road, Parkville, This is the author manuscript accepted for publication and has undergone full peer review but has not been through the copyediting, typesetting, pagination and proofreading process, which may lead to differences between this version and the Version of Record. Please cite this article as doi: $10.1111 /$ jpc.14426

This article is protected by copyright. All rights reserved. 
3052, Victoria, Australia. Email: Sharon.Goldfeld@,rch.org.au. Phone: +61 393456408. Fax: +6139345 5900 .

This article is protected by copyright. All rights reserved. 


\title{
ACKNOWLEDGEMENTS
}

We thank the APRN paediatricians who completed the 2013 multi-topic survey. The survey was funded by the 2013 Royal Australasian College Physicians Fellows Award. Murdoch Children's Research Institute research is supported by the Victorian Government's Operational Infrastructure Support Program. Professor Goldfeld is supported by Australian National Health and Medical Research Council (NHMRC) Career Development Fellowship 1082922.

\section{CONFLICT OF INTEREST}

None to declare.

\begin{abstract}
Aim: Many Australian children have dental decay in their deciduous teeth. Poor oral health can negatively impact a child's ability to eat, speak, sleep and socialise, with adverse impacts later in life. Paediatricians are well placed to examine children's teeth, and to provide advice and education about oral health. From a sample of Australian paediatricians we aimed to determine: (i) self-reported oral health knowledge and skills; (ii) frequency of office-based oral health-related discussions; (iii) perceived role of paediatricians; and (iv) barriers to oral health-related discussions.
\end{abstract}

Methods: Members of a national network of paediatricians - the Australian Paediatric Research Network - completed a multi-topic survey, which included questions designed to assess oral health knowledge, current practice, and barriers to oral health-related discussions.

Results: Of 430 active members, 178 (41\%) completed the survey. Few paediatricians reported very good/excellent ability to assess plaque build-up (8\%) and dental caries (17\%). Only $10 \%$ reported broaching the issue of oral health with all patients. Significant barriers included lack of professional training (52\%) and other more pressing issues needing to be addressed (67\%).

This article is protected by copyright. All rights reserved. 
Conclusions: The increasing (and inequitable) rates of dental decay for Australian children mean that paediatricians should play a key role in the management of children's oral health. Many paediatricians reported a lack of specific training in oral health and limited ability to assess children and educate families. Despite the traditional divide between medicine and oral health, this study highlights the opportunity for Australian paediatricians to improve oral health early intervention in the consultation room and beyond.

Keywords: oral health, dental caries, child, pediatricians, surveys and questionnaires 


\section{WHAT IS ALREADY KNOWN ON THIS TOPIC}

1. In Australia, more than half of all 6-year-old children have dental decay in their deciduous teeth

2. Childhood caries represents a serious public health problem, particularly in disadvantaged subpopulations

3. Paediatricians are well placed to educate and examine regarding children's oral health

\section{WHAT THIS PAPER ADDS}

1. Many paediatricians report a lack of specific training in oral health and limited ability to assess children and educate families

2. Most paediatricians would welcome more training around oral health and dental caries

3. Additional training for Australian paediatricians could improve early intervention and prevention of dental caries

This article is protected by copyright. All rights reserved. 


\section{Oral health care: The experience of Australian paediatricians}

\section{INTRODUCTION}

Oral health conditions affect approximately 3.9 billion people globally.[1] In 2010, untreated dental caries in permanent teeth was established as the most prevalent condition worldwide.[2] At that time, more than half of all 6-year-old children in Australia had dental decay in their deciduous teeth and $48 \%$ of 12 -year-olds had history of decay in their permanent teeth.[3] There has been a steady rise in dental caries in Australian children over the last two decades.[4] For example, using the dmft index, a number given as the total number of teeth or surfaces that are decayed (d), missing (m), or filled (f) in an individual, the deciduous decay experience in 6-year-old children increased from 1.45 in 1996 to 2.58 in 2010.[3] While 12-year-old children in Australia have less caries experience (1.1 in 2006) compared to the OECD average (1.6), it is higher than Germany (0.7), United Kingdom (0.7), Sweden (1.0) and Canada (1.0).[3, 5, 6]

Poor oral health can negatively impact a child's ability to eat, speak, sleep and socialise, which may then have adverse impacts later in life.[7] Early childhood caries (ECC; one or more decayed, missing or filled tooth surfaces under six years of age)[8] progresses more rapidly than in adult teeth,[9, 10] can cause severe toothache,[10-12] and predicts future caries later in childhood and into adulthood.[7, 8, 13-16]

Childhood caries represents a serious public health problem, particularly in disadvantaged subpopulations (i.e., Aboriginal or Torres Strait Islanders, low income families, children living in rural and remote areas, and children with special health care needs).[7, 9, 10, 17, 18] The oral health of Aboriginal children in Australia is worsening, with twice the level of dental caries compared to non-Aboriginal children.[10] A higher proportion of children from households where parents had low income or education do not visit a dentist before five years of age, have irregular dental visiting patterns, and do not brush their teeth twice a day.[17] Poor oral health has also been associated with chronic diseases such as childhood obesity.[19-21] 
The most influential factors in the formation of dental caries are: accumulation and retention of bacterial dental plaque; frequency of exposure to fermentable carbohydrates and dietary acids; factors affecting embryological formation of tooth germ formation; presence of natural protective factors such as saliva; and exposure to a low level of fluoride.[22-25] Social factors such as the caregiver's education level and reported family income have been inversely associated with ECC.[26, 27]

The Royal Australasian College of Physicians (RACP) released a position statement in 2012 highlighting that "paediatric oral health is one of the areas of greatest health inequity in Australia and New Zealand".[7] As many children (especially those in vulnerable subpopulations) do not make a dentist visit prior to starting school,[17] it is important that other health professionals feel sufficiently expert to examine the mouth, providing advice and referring as necessary. Given this recommendation, it seems sensible that paediatricians and general practitioners alike should be aware of the emerging and increasing oral health issues amongst the paediatric population, particularly given the comorbidity between chronic diseases such as obesity and dental caries.[19-21] However, studies have shown that while most paediatricians acknowledge that they should educate families about oral health and assess children for dental caries, many report a lack of confidence in their abilities and a lack of training.[28, 29] As such, the RACP recommended integrating knowledge of oral health into training for paediatricians to improve early intervention, particularly in vulnerable subpopulations.[7]

To determine the current state of paediatric knowledge and potential integration of oral health care into paediatric practice, we surveyed a sample of Australian general paediatricians (through the Australian Paediatric Research Network-APRN) to ascertain their (i) selfreported oral health knowledge and skills; (ii) frequency of oral health-related discussions; (iii) perceived role of paediatricians; and (iv) barriers to oral health-related discussions.

\section{MATERIALS AND METHODS}




\section{Design, setting and participants}

The APRN was established in 2007 and is a national network of paediatricians committed to facilitating high-quality multi-site research into common paediatric conditions in secondary care settings.[30, 31] APRN members were recruited from the 1,006 general paediatricians registered in 2007 with the RACP.

In 2013, APRN members were invited to answer questions on oral health as part of the annual multi-topic survey. Over a 4-month period from March to June 2013, the survey was administered via Research Electronic Data Capture, a secure, web-based application supporting data capture for research studies.[32] Ethics approval was obtained by The Royal Children's Hospital Human Research Ethics Committee (33021).

\section{Main outcome measures}

\section{Oral health measures}

The survey included questions designed to assess oral health knowledge, current practice, and barriers; adapted from the American Academy of Pediatrics Periodic Survey of Fellows focused on oral health within paediatric practices.[28] The survey consisted of a series of questions measured using Likert scales. Paediatricians reported on their barriers to oral health-related discussions and self-reported knowledge and skills, frequency of oral health discussions and perceived role of paediatricians, and interest in training and education to assist in oral health-related discussions with parents.

\section{Demographic measures}

Paediatrician characteristics (age, gender, work hours, location practice type, practice location, and postcode of paediatrician's primary practice) were obtained from the APRN database. The paediatrician's practice postcode was used to measure socioeconomic status with the Socio-Economic Indexes for Areas (SEIFA) Index of Relative Disadvantage.[33] Higher SEIFA scores indicate less disadvantage.

\section{Data management and statistical analysis}


All analyses were conducted using STATA version 15.[34]. Descriptive statistics were used for all demographic variables. The Pearson chi-square statistic was used to assess the difference in responses for categorical data.

\section{RESULTS}

\section{Characteristics of responders and non-responders}

A total of 178 (41\%) of 430 paediatricians responded (52\% female), 58\% worked full-time and $76 \%$ in a public hospital. Survey responders significantly differed in age, and were more likely to work full-time than non-responders (Table 1).

\section{Self-reported knowledge and skills}

There were substantial differences between paediatric training in child development and oral health related topics; $91 \%$ for 'moderate' or 'significant' amounts of training in child development compared to $23 \%$ who had similar amounts of training in stages of teeth development, and only $7 \%$ in plaque and dental caries. Only $25 \%$ identified all major risk factors for caries correctly, while 51\% correctly identified all the ways dental caries can be prevented (Table 2).

In contrast to self-related ability (e.g., $8 \%$ reported their ability to assess plaque build-up as 'very good/excellent' (Table 3)), around $60 \%$ of responders reported 'very good/excellent' ability to inform parents on the oral health effects of putting their child to bed with a bottle, and on the oral health effects of sugary food and drink.

\section{Frequency of oral health-related discussions}

Almost all responders (93\%) reported they had children with oral health problems in their practice (Table 2), at least some of which were moderate to severe (Table 4). Reported general assessments would regularly include chest $(71 \%)$ or cardiac $(77 \%)$ examinations; however, only $40 \%$ would include an examination of oral health.

\section{Perceived role of paediatricians}


While responders almost universally (97\%) thought they should discuss with parents the oral health effects of both a) putting their child to bed with a bottle and b) sugary food and drink (Table 2), only $10 \%$ reported that they broach the issue of oral health with all patients (Table $4)$.

\section{Barriers to oral health-related discussions}

Responders identified a number of significant barriers to oral health-related discussions (Table 5), such as a lack of professional training (52\%), other more pressing issues needing to be addressed (67\%), and concerns accessing public, private and paediatric specific dentists and practices $(27-49 \%)$.

Most responders wanted to increase their oral health knowledge (85\%). A desire for increased teaching around oral health and dental caries was expressed both prior to completion of postgraduate specialist training (pre-FRACP; 89\%) and after completion (postFRACP; 74\%). Multiple modes of delivery were preferred, such as via email (45\%), access to information on the RACP website (33\%), and a feature presentation on Paediatric Updates $(55 \%)$.

\section{DISCUSSION}

Despite dental caries being one of the most prevalent childhood conditions, [2] this is the first national survey to report the experience of Australian paediatricians in managing children's oral health. Almost all paediatricians reported having children with oral health problems in their practice, but often did not address them, due to barriers regarding time and options for referral. It was evident that paediatricians had significant gaps in their knowledge of oral health but encouragingly reported a desire and willingness for further training.

In contrast to other aspects of paediatric examination, many paediatricians reported their ability to assess plaque build-up and dental caries as poor. This inability to assess oral health, and specifically children's teeth, appears to be a more global paediatric issue. In the United States, where paediatricians deliver primary care, a comparable survey of paediatricians 
found that many did not rate their ability to identify dental caries $(59 \%)$ or plaque $(77 \%)$ as good or excellent.[28] Similarly, a survey of postgraduate paediatric trainees in the United Kingdom reported that most respondents (85\%) rated their ability to identify dental decay as three or below (on a five-point scale), and $47 \%$ reported a 'poor' ability to identify dental plaque.[35] Together, these studies indicate that while paediatricians do have knowledge about oral health, there are significant gaps in their ability to confidently assess children's oral health.

Not surprisingly, oral health education has traditionally not been prioritised in medical student or post-graduate teaching curricula globally.[3, 36-38] In fact oral health has mostly not been seen as part of the purview for medical practitioners in a strange disconnect from the rest of health and development.[39] To address this knowledge and practice gap, oral health education is vital across the health professions; paediatricians do not stand alone in their lack of comfort to address oral health issues.[40] An online education program for midwives developed in New South Wales has been shown to significantly improve oral health knowledge, particularly in dental pathology and its impact on birth and infant outcomes.[41] The majority of participating midwives also reported an increase in confidence around incorporating oral health into their practice and referring women to dental services. Yet surveys of medical schools have shown a lack of comprehensive instruction in dental topics $[36,37]$ and an absence of standardised learning objectives, teaching methodology and assessment.[38]

Although almost all paediatricians reported having children with oral health problems in their practice, less than half consistently included oral health as part of a general assessment. This is likely to be an underestimate. Nevertheless, the majority of paediatricians surveyed believe they have a role in broaching the issue of oral health. Identification of early plaque development would provide an opportunity to possibly prevent decay. Where decay has occurred, the paediatrician could then refer and advocate for early dental review. Further, health practitioners may find that, by treating oral health problems, other systemic issues may improve or be avoided.[42] State and federal health services have begun to recognise that 
child health professionals (such as paediatricians, child and family health nurses and general practitioners) are often better placed than oral health professionals to access, engage with and guide parents about the importance of oral health, because of their direct involvement through early childhood reviews and immunisations.[18, 43] As early, preventative action is more cost-effective than late intervention,[44-46] it is important that change within our health system occurs. Paediatricians are well suited to drive this change.

Perhaps at the heart of the reluctance to examine children's mouths and teeth was that more than half the responders felt it was difficult to refer onwards to public, private, and paediatric specific dentists and dental practices. Previous research has shown that clinicians are more likely to refer children if they report confidence with the referral environment.[47] The concerns of paediatricians are well founded. In 2013, there were approximately 56 dentists per 100,000 people in Australia; around 10\% $(\mathrm{n}=1403)$ of employed dentists were specialists, and only 94 of these were paediatric dentists.[3] In Victoria, dental ambulatory care sensitive conditions (ACSCs) have the highest rate of all ACSC hospital admissions for children, and more than $\$ 9$ million is spent on avoidable dental ACSCs for children each year.[48] These are admissions that would have been avoidable with good community primary (dental) care.

Compounding the dental service availability issue is the complexity of access. Medicare, Australia's public funded health system, has for the most part restricted dental health coverage. Whereas specialist services are funded in part by Medicare, the majority of dental reviews are self-funded or paid by a private health fund, often with remaining out of pocket expenses.[49] Public dental practices have long waiting lists[50] and state initiatives such as school dental services typically target children in primary school, leaving the majority of preschool or high school students without public dental care.[3] Almost half of all children who visit a school dentist already have dental caries,[51] highlighting the importance of early childhood review and intervention. More recent changes in federal government policies in 2014 have allowed dental practitioners, private and public alike, to bill with a provider number linked to Medicare. The Child Dental Benefits Schedule (CDBS) allows children aged between 2-17 years to benefit from basic dental services capped at $\$ 1000$ over two 
years.[52] The CDBS is means tested, and children whose family receive government benefits such as Family Tax benefit A or B are eligible. In the first year of implementation, only $29 \%$ of eligible children accessed the program.[53] With this policy, it is even more crucial (and opportunistic) that health practitioners (including paediatricians) assess their patient's oral health, identify signs of plaque deposition or decay and refer in a timely manner. Underutilisation of the scheme may lead to further restrictions or its cessation.

Our study has several strengths, including being the first national survey to provide information about the experience of Australian paediatricians in managing children's oral health. APRN responders were generally similar to non-responders, improving the generalisability of our results within the APRN membership [31] although we acknowledge non-members may have differing views. Further limitations include the modest response rate, particularly with regard to representation of younger paediatricians (aged 25-34 years). As such, we cannot determine whether there have been any changes to medical and postgraduate teaching in recent years to reflect oral health practices. In an effort to provide a more socially desirable response, some pediatricians may have overestimated the frequency with which they participate in oral health-related activities in their practice. Finally, pediatricians' responses may not represent patients' actual experiences.

\section{CONCLUSION}

The high and increasing rates of dental caries in Australia's children over the last two decades suggests there is an urgent need to systematically address the unnatural divide between children's teeth and their overall health and development. Paediatricians should play a key role in the prevention and early intervention of children's dental caries. The lack of specific training in oral health and limited ability to assess children and educate families provides an opportunity for paediatric and dental collaboration. Although establishing sufficient dental practice responses is still emerging, it is essential to consider training for Australian paediatricians now to improve oral health early intervention in the consultation room and beyond in the next decade. 


\section{REFERENCES}

[1] Richards D. Oral diseases affect some 3.9 billion people. Evidence Based Dentistry. 2013; 14: 35 .

[2] Kassebaum N, Bernabé E, Dahiya M, Bhandari B, Murray C, Marcenes W. Global burden of untreated caries: A systematic review and metaregression. Journal of Dental Research. 2015; 94: 650-658.

[3] Chrisopoulos S, Harford S, Ellershaw A. Oral health and dental care in Australia: Key facts and figures 2015. Australian Institute of Health and Welfare, Canberra, Australia, 2016.

[4] Armfield J, Slade G, Spencer A. Dental health of Australia's teenagers and pre-teen children: the Child Dental Health Survey, Australia 2003-04. Australian Institute of Health and Welfare, Canberra, Australia, 2010.

[5] Canadian Dental Association. The state of oral health in Canada. Author, Ontario, Canada, 2017.

[6] World Dental Federation. FDI data hub for global oral health. Author, Switzerland, 2018.

[7] Goldfeld S, Cameron A, Doyle K, et al. The Royal Australasian College of Physicians oral health in children and young people position statement. Royal Australasian College of Physicians, Sydney, Australia, 2012.

[8] Gussy M, Ashbolt R, Carpenter L, et al. Natural history of dental caries in very young Australian children. International Journal of Paediatric Dentistry. 2015; 26: 173-183.

[9] Davies G. Early childhood caries - A synopsis. Community Dentistry and Oral Epidemiology. 1998; 26: 106-116.

[10] Christian B, Blinkhorn A. A review of dental caries in Australian Aboriginal children: The health inequalities perspective. Rural and Remote Health. 2012; 12: 2032.

[11] Slade G, Spencer A, Davies M, Burrow D. Intra-oral distribution and impact of caries experience among South Australian school children. Australian Dental Journal. 1996: 343350 .

This article is protected by copyright. All rights reserved. 
[12] Nuttall N, Steele J, Evans D, Chadwick B, Morris A, Hill K. The reported impact of oral condition on children in the United Kingdom, 2003. British Dental Journal. 2006; 200: $551-555$.

[13] Haugejorden O, Birkeland J. Evidence for reversal of the caries decline among Norwegian children. International Journal of Paediatric Dentistry. 2002; 12: 306-315.

[14] Tennant M, Namjoshi D, Silva D, Codde J. Oral health and hospitalization in Western Australian children. Aust Dent J. 2000; 45: 204-207.

[15] Grindefjord M, Dahllof G, Modeer T. Caries development in children from 2.5 to 3.5 years of age: A longitudinal study. Caries Research. 1995; 29: 449-454.

[16] Thomson W, Poulton R, Milne B, Caspi A, Broughton J, Ayers K. Socioeconomic inequalities in oral health in childhood and adulthood in a birth cohort. Community Dentistry and Oral Epidemiology. 2004; 32: 345-353.

[17] Do L, Spencer A, eds. Oral health of Australian children: The National Child Oral Health Study 2012-2014. University of Adelaide Press: Adelaide, Australia, 2016.

[18] Australian Health Ministers' Conference, National Advisory Committee on Oral Health, South Australia Department of Health. Healthy mouths, healthy lives: Australia's national oral health plan 2004-2013. South Australian Department of Health, Adelaide, 2004.

[19] Li W, Hussein Musa T, Gao R, et al. Association between BMI and dental caries among school children and adolescents in Jiangsu Province, China. Biomedical and Environmental Sciences. 2017; 30: 758-761.

[20] Carson S, Abuhaloob L, Richards D, Hector M, Freeman R. The relationship between childhood body weight and dental caries experience: An umbrella systematic review protocol. Systematic Reviews. 2017; 6.

[21] Tubert-Jeannin S, Pichot H, Rouchon B, Pereira B, Hennequin M. Common risk indicators for oral diseases and obesity in 12-year-olds: A South Pacific cross sectional study. BMC Public Health. 2018; 18.

[22] Mount G, Hume W. Preservation and restoration of tooth structure. 2nd ed. Knowledge Books and Software, Sandgate, 2005. 
[23] Berkowitz R. Causes, treatment and prevention of early childhood caries: A microbiologic perspective. Journal of the Canadian Dental Association. 2003; 69: 304-307. [24] Qin M, Li J, Zhang S, Ma W. Risk factors for severe early childhood caries in children younger than 4 years old in Beijing, China. Pediatric Dentistry. 2008; 30: 122-128. [25] Leong P. A systematic review of risk factors during first year of life for early childhood caries. International journal of paediatric dentistry (0960-7439). 2013; 23: 235. [26] Tang J, Altman D, Robertson D, O'Sullivan D, Douglass J, Tinanoff N. Dental caries prevalence and treatment levels in Arizona preschool children. Public Health Reports. 1997; 112: 319-329.

[27] Reisine S, Psoter W. Socioeconomic status and selected behavioral determinants as risk factors for dental caries. Journal of Dental Education. 2001; 65: 1009-1016.

[28] Lewis C, Boulter S, Keels M, et al. Oral health and pediatricians: Results of a national survey. Academic Pediatrics. 2009; 9: 457-461.

[29] Quinonez R, Kranz A, Lewis C, et al. Oral health opinions and practices of pediatricians: Updated results from a national survey. Academic Pediatrics. 2014; 14: 616623.

[30] Hiscock H, Efron D, Wasserman R, Wake M. Power to the paediatricians: The Australian Paediatric Research Network is born. Journal of Paediatrics and Child Health. 2012; 48: 6-9.

[31] Rudolph S, Hiscock H, Price A, et al. What research questions matter to Australian paediatricians? National Delphi Study. Journal of Paediatrics and Child Health. 2009; 45: 704-710.

[32] Harris P, Taylor R, Thielke R, Payne J, Gonzalez N, Conde J. Research Electronic Data Capture (REDCap) - A metadata-driven methodology and workflow process for providing translational research informatics support. Journal of Biomedical Informatics. 2009; 42: 377-381.

[33] Pink B. Information paper: an introduction to socio-economic indexes for areas (SEIFA), 2006. Canberra: Australian Bureau of Statistics (ABS). 2008.

[34] StataCorp. Stata Statistical Software: Release 15. StataCorp LLC, College Station, TX, 2017. 
[35] Kalkani M, Ashley P. The role of paediatricians in oral health of preschool children in the United Kingdom: A national survey of paediatric postgraduate specialty trainees. European Archives of Paediatric Dentistry. 2013; 14: 319-324.

[36] Curtis J, Garrison R, Camp M. Dentistry in medical education: Results of a comprehensive survey. Journal of Medical Education. 1985; 60: 16-20.

[37] Abbott B, Zybutz C, Scott K, Eberhard J, Widmer R. A review of the hours dedicated to oral health education in medical programmes across Australia. Internal Medicine Journal. In press.

[38] Ahmad M, Abuzar M, Razak I, Rahman S, Borromeo G. Educating medical students in oral health care: current curriculum and future needs of institutions in Malaysia and Australia. European Journal of Dental Education. 2017; 21: e29-e38.

[39] Otto M. Teeth: The story of beauty, inequality, and the struggle for oral health in America. The New Press, New York, NY, 2017.

[40] Lim M, Riggs E, Shankumar R, Marwaha P, Kilpatrick N. Midwives' and women's views on accessing dental care during pregnancy: An Australian qualitative study. Australian Dental Journal. 2018; 63: 320-328.

[41] George A, Lang G, Johnson M, et al. The evaluation of an oral health education program for midwives in Australia. Women Birth. 2016; 29: 208-213.

[42] Cooley R, Sanders B. The pediatrician's involvement in prevention and treatment of oral disease in medically compromised children. Pediatric Clinics of North America. 1991; 38: $1265-1288$.

[43] NSW Health. Early childhood oral health guidelines for child health professionals. 3rd edn, 2014.

[44] Atkins C, Thomas T, Lenaker D, Day G, Hennessy T, Meltzer M. Cost-effectiveness of preventing dental caries and full mouth dental reconstructions among Alaska Native children in the Yukon-Kuskokwim delta region of Alaska. Journal of Public Health Dentistry. 2016; 76: 228-240.

[45] Ramos-Gomez F, Huang G, Masouredis C, Braham R. Prevalence and treatment costs of infant caries in Northern California. ASDC Journal of Dentistry for Children. 1996; 63: 108-112. 
[46] Kelly M, Bruerd B. The prevalence of baby bottle tooth decay among two native American populations. Journal of Public Health Dentistry. 1987; 47: 94-97.

[47] dela Cruz G, Rozier G, Slade G. Dental screening and referral of young children by pediatric primary care providers. Pediatrics. 2004; 114: 1329-1330.

[48] Calache J, Hopcraft M, Martin J. Minimum intervention dentistry - A new horizon in public oral health care. Australian Dental Journal. 2013; 58: 17-25.

[49] Australian Institute of Health and Welfare. Health Expenditure Australia 2010-11.

Health and welfare expenditure series no. 47. Cat. no. HEW 56. Author, Canberra, Australia, 2012 .

[50] Australian Institute of Health and Welfare. A discussion of public dental waiting times information in Australia: 2013-14 to 2016-17. Cat no. DEN 230. Author, Canberra, Australia, 2018.

[51] Australian Institute of Health and Welfare. Oral health and dental care in Australia: Key facts and figures trends 2014. Cat. no. DEN 228. Author, Canberra, Australia, 2014. [52] Department of Health. The Child Dental Benefits Schedule. 2014.

[53] Department of Health. Report on the third review of the Dental Benefits Act 2008. Author, Canberra, Australia, 2016.

This article is protected by copyright. All rights reserved. 
Table 1. Characteristics of Australian Paediatric Research Network (APRN) survey responders and non-responders to the multi-topic survey.

\begin{tabular}{|c|c|c|c|}
\hline & $\begin{array}{c}\text { APRN survey } \\
\text { responders }(n=178)\end{array}$ & $\begin{array}{l}\text { APRN survey non- } \\
\text { responders }(n=252)\end{array}$ & \\
\hline & $\%(n)$ & $\%(n)$ & $p$ \\
\hline Female gender & $51.7(92)$ & $44.8(113)$ & 0.16 \\
\hline Age & & & 0.02 \\
\hline $25-34$ & $0.6(1)$ & $6.5(16)$ & \\
\hline $35-44$ & $42.6(75)$ & $38.6(95)$ & \\
\hline $45-54$ & $30.1(53)$ & $33.3(82)$ & \\
\hline $55-64$ & $23.3(41)$ & $17.9(44)$ & \\
\hline $65+$ & $3.4(6)$ & $3.7(9)$ & \\
\hline Works part-time & $42.1(75)$ & $53.2(134)$ & 0.02 \\
\hline \multicolumn{4}{|l|}{ Practice setting $\dagger$} \\
\hline Academic & $15.2(27)$ & $16.3(41)$ & 0.76 \\
\hline Private practice & $34.8(62)$ & $35.3(89)$ & 0.92 \\
\hline Public hospital & $76.4(136)$ & $73.0(184)$ & 0.43 \\
\hline Community health & $10.1(18)$ & $5.6(14)$ & 0.08 \\
\hline Practice location & & & 0.63 \\
\hline Metropolitan & $71.4(122)$ & $67.4(157)$ & \\
\hline Regional & $22.8(39)$ & $27.0(63)$ & \\
\hline Rural & $5.9(10)$ & $5.6(13)$ & \\
\hline SEIFA disadvantage & & & 0.64 \\
\hline High & $36.1(62)$ & $32.5(79)$ & \\
\hline Medium & $39.0(67)$ & $38.7(94)$ & \\
\hline
\end{tabular}


Low

SEIFA=Socio-Economic Indexes for Areas. $\uparrow$ Paediatricians were able to answer more than one type of practice.

This article is protected by copyright. All rights reserved. 
Table 2. Frequency data for paediatrician responses on self-reported knowledge and skills, frequency of children with oral health problems, and perceived role of paediatricians.

APRN survey

responders

$(n=178)$

$\%(n)$

Major risk factors for caries $\uparrow(\%$ selected)

Bottle feeding (correct response)

Breast feeding (incorrect response)

Excess salivation and drooling (incorrect response)

Increased dietary sucrose (correct response)

Retained milk in the mouth (correct response)

Chalky teeth (enamel defects) (correct response)

$56.0(93)$

How dental caries can be prevented $\dagger(\%$ selected $)$

Decreasing dietary glucose (correct response)

$69.8(120)$

Regular brushing and flossing (correct response)

Fluoridation of water (correct response)

Immunisation (incorrect response)

Early recognition of plaque (correct response)

How often would you look for dental caries (\% selected)

In less than half of my patients

In more than half of my patients

Any children with oral health problems in your practice in last 3 years $(\%$ selected $)$

No

This article is protected by copyright. All rights reserved. 
Number of children in your practice with dental caries in last 3 years $(\%$ selected $)$

1-10 children

11-99 children

100-1000 children

Ages of most of these children with dental caries (\% selected)

Preschool aged

School aged

Do you think you should: $\uparrow$ (\%yes)

Broach the issue of oral health with parents yourself

$78.6(125)$

Discuss the issue of oral health when parents broach it

$97.5(153)$

Assess dental caries and plaque build-up

$68.8(110)$

Look for gingivitis and/or ulcers

Inform parents on oral health effects of putting their child to

bed with a bottle

Inform parents on the oral health effects of sugary food and drink

Instruct parents in tooth brushing

$48.1(76)$

$\dagger$ Data not mutually exclusive.

This article is protected by copyright. All rights reserved. 
Table 3. Perceived ability to perform oral health assessments.

\section{APRN survey responders}

$(n=178)$

\section{Very good/excellent}

$\%$ (n)

Broach oral health issue with parents

$33.5(53)$

Discuss oral health issue when parents broach it

$40.8(64)$

Assess dental caries

$17.1(27)$

Assess plaque build-up

Look for gingivitis and/or oral ulcers

$26.1(41)$

Inform parents on oral health effects of putting child to bed with a bottle

Inform patients/ parents on oral health effects of sugary food/drink

$60.5(95)$

Instruct parents in tooth brushing

$19.8(31)$ 
Table 4. Perceived role of paediatricians.

\section{APRN survey responders}

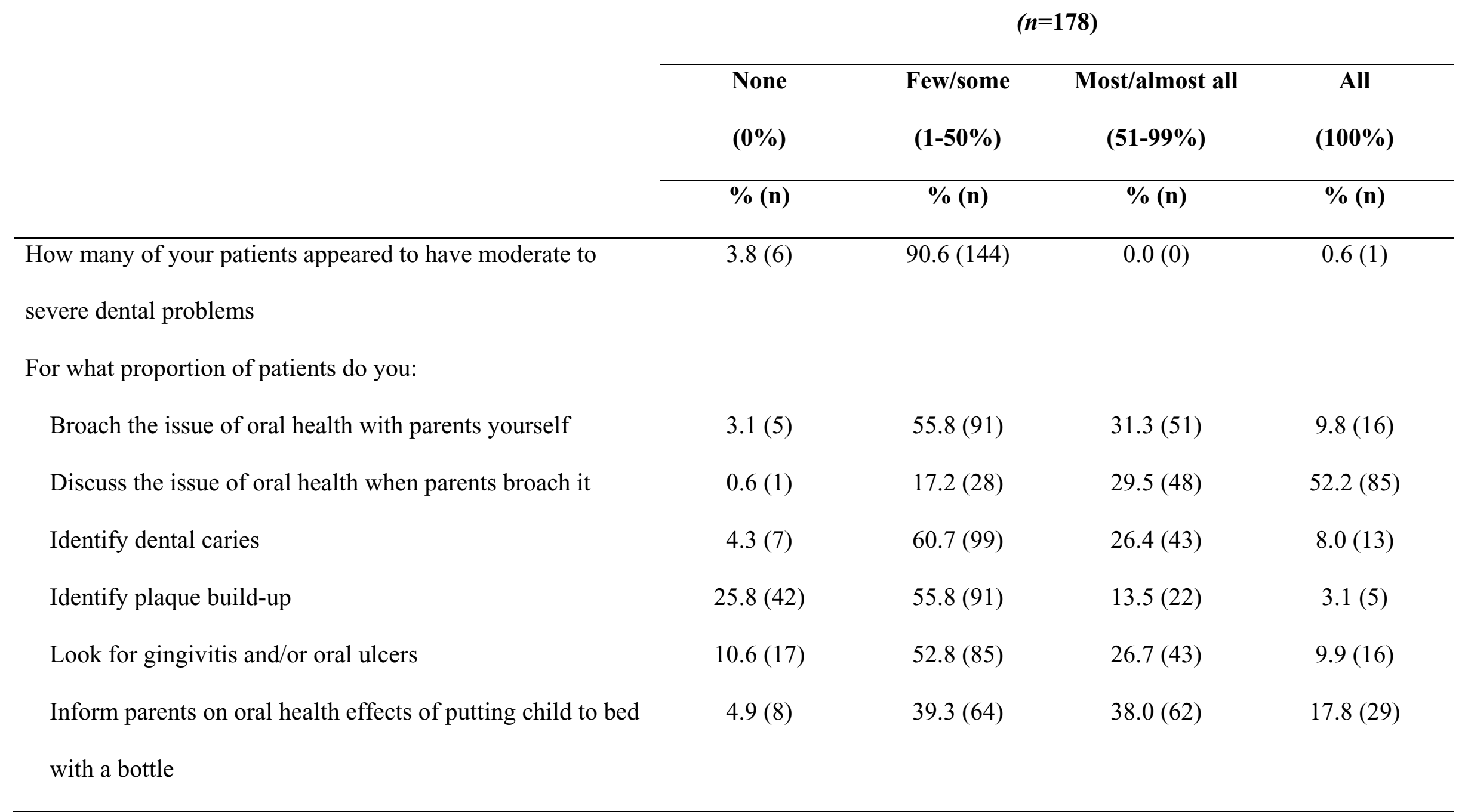




\begin{tabular}{lccc}
\hline Inform patients and parents on the oral health effects of & $4.3(7)$ & $41.1(67)$ & $36.8(60)$ \\
sugary food and drink & & & \\
Inform parents how to brush their children's teeth correctly & $29.6(48)$ & $50.6(82)$ & $17.9(29)$ \\
Assessed parents' oral health & $61.7(100)$ & $30.9(50)$ & $4.9(8)$
\end{tabular}

Note: The survey included a "don't know” response option, but as numbers were very small $(<5 \%)$ this was omitted from the table. 
Table 5. Barriers to participation in oral health activities.

APRN survey responders

$(n=178)$

\begin{tabular}{ccc}
\hline Significant & Moderate/ & Nil \\
& Minimal & \\
\hline$\%(n)$ & $\%(n)$ & $\%(n)$
\end{tabular}

\begin{tabular}{|c|c|c|c|}
\hline \multicolumn{4}{|l|}{ How important are these barriers to your participation in oral health activities? } \\
\hline Lack of professional training in oral health care & $51.9(84)$ & $47.5(77)$ & $0.6(1)$ \\
\hline Inadequate time during consultation & $48.8(79)$ & $50.0(81)$ & $1.2(2)$ \\
\hline Other more pressing issues needing to be addressed & $66.5(107)$ & $32.3(52)$ & $1.2(2)$ \\
\hline Inability to bill separately for oral health assessment or counselling & $10.8(17)$ & $39.2(62)$ & $50.0(79)$ \\
\hline Accessing public dental practices & $49.4(80)$ & $40.7(66)$ & $9.9(16)$ \\
\hline Accessing private dental practices & $27.3(44)$ & $59.0(95)$ & $13.7(22)$ \\
\hline Accessing paediatric specific dentists & $38.5(62)$ & $50.3(81)$ & $11.2(18)$ \\
\hline
\end{tabular}


Original article

\title{
Oral health care: The experience of Australian paediatricians
}

\author{
Archana Koirala, \\ archana.koirala@heath.nsw.gov.au \\ Elodie O'Connor ${ }^{\mathrm{c}}$ \\ elodie.oconnor@mcri.edu.au \\ Richard Widmer $^{\mathrm{d}}$ \\ richard.widmer@health.nsw.gov.au \\ Nicky Kilpatrick, e,f,g \\ nicky@bassdata.com.au \\ Sharon Goldfeld ${ }^{\mathrm{c}, \mathrm{f}}$ \\ sharon.goldfeld@rch.org.au
}

\begin{abstract}
Affiliations: ${ }^{a}$ Centre of Infectious Diseases and Microbiology, Sydney, Australia. ${ }^{b}$ University

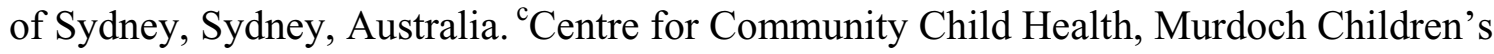
Research Institute, Royal Children's Hospital, Melbourne, Australia; ${ }^{\mathrm{d}}$ Department of Paediatric Dentistry, Children's Hospital at Westmead, Sydney, Australia; ${ }^{\mathrm{e}}$ Department of Plastic and Maxillofacial Surgery, Royal Children's Hospital, Melbourne, Australia; ${ }^{f}$ Department of Paediatrics, University of Melbourne, Melbourne, Australia; ${ }^{g}$ Plastic Surgery Research, Murdoch Children's Research Institute, Royal Children's Hospital, Melbourne, Australia.
\end{abstract}

Address correspondence to: Professor Sharon Goldfeld, Centre for Community Child Health, Royal Children's Hospital, 2 East Clinical Offices, 50 Flemington Road, Parkville, 3052, Victoria, Australia. Email: Sharon.Goldfeld@,rch.org.au. Phone: +61 393456408. Fax: +6139345 5900 .

This article is protected by copyright. All rights reserved. 


\section{ACKNOWLEDGEMENTS}

We thank the APRN paediatricians who completed the 2013 multi-topic survey. The survey was funded by the 2013 Royal Australasian College Physicians Fellows Award. Murdoch Children's Research Institute research is supported by the Victorian Government's Operational Infrastructure Support Program. Professor Goldfeld is supported by Australian National Health and Medical Research Council (NHMRC) Career Development Fellowship 1082922.

\section{CONFLICT OF INTEREST}

None to declare. 


\section{University Library}

\section{- M M N E R VA A gateway to Melbourne's research publications}

Minerva Access is the Institutional Repository of The University of Melbourne

Author/s:

Koirala, A;O'Connor, E;Widmer, R;Kilpatrick, N;Goldfeld, S

Title:

Oral health care: The experience of Australian paediatricians

Date:

2019-11-01

Citation:

Koirala, A., O'Connor, E., Widmer, R., Kilpatrick, N. \& Goldfeld, S. (2019). Oral health care:

The experience of Australian paediatricians. JOURNAL OF PAEDIATRICS AND CHILD HEALTH, 55 (11), pp.1374-1380. https://doi.org/10.1111/jpc. 14426.

Persistent Link:

http://hdl.handle.net/11343/285578 